Proc. Indian Acad. Sci., Vol. C2, Part 3, September 1979, pp. 357-363. (C) Printed in India.

\title{
Studies in biogas technology. Part I. Performance of a conventional biogas plant
}

\author{
P RAJABAPAIAH*, K V RAMANAYYA*, S R MOHAN* and \\ AMULYA KUMAR N REDDY** \\ *Biogas Laboratory, ASTRA \\ **Department of Inorganic and Physical Chemistry, Indian Institute of Science, \\ Bangalore 560012
}

MS received 2 July 1979; revised 20 July 1979

\begin{abstract}
This paper gives an account of a conventional $5.66 \mathrm{~m}^{3} /$ day ( $200 \mathrm{cubic} \mathrm{ft} / \mathrm{day}$ ) biogas plant which has been instrumented, operated and monitored for $2 \frac{1}{2}$ years. The observations regarding input to the plant, sludge and biogas outputs, and conditions inside the digester, have been described. Three salient features stand out. First, the observed average daily gas yield is much less than the rated capacity of the plant. Secondly, the plants show ease of operation and a very slow response to reductions and cessations of dung supply. Thirdly, the unexpectedly marked uniformity of density and temperature inside the digester indicates the almost complete absence of the stratification which is widely believed to take place; hence, biogas plants may be treated as isothermal, ' uniform ' density, most probably imperfectly mixed, fed-batch reactors operating at the mean ambient temperature and the density of water.
\end{abstract}

Keywords. Cattle wastes; biogas plant; anaerobic digestion; manure; sludge; yield; gas production; material balance; nitrogen; $\mathrm{pH}$; temperature; density; plant-scale studies; stratification; reactor; steady-state reactor; batch reactor; constant flow reactor; completely mixed reactor; stability; solids; total solids; volatile solids.

\section{Introduction}

The potential of biogas plants, as a source of both energy and fertiliser, was first publicised by the Khadi and Village Industries Commission (KVIC) and then clearly revealed in the techno-economic review of Prasad et al (1974). This study, along with others on the same subject (Mahkijani \& Poole 1975; Reddy \& Krishna Prasad 1977), showed that biogas plants could play a major role in overcoming the long-standing 'energy crisis' in rural areas. At the same time, many state-of-the-art reviews highlighted several important lacunae in the knowledge-base of this promising technology (Kirsch \& Sykes 1971; Meynell 1976; Pyle 1978; Prasad et al 1974).

A programme of work was therefore initiated with four objectives: (i) to obtain reliable information on the behaviour and performance of conventional biogas plants of the KVIC design; (ii) to develop a theory for the optimisation of the dimensions of biogas plants; (iii) to understand the heat transfer processes in these plants and (iv) to develop a simple, inexpensive technique for heating biogas digesters.

The progress achieved with respect to these four objectives is described in this paper, each part of which focusses on one of the objectives. This first part deals with the conventional plant of KVIC design that was set up at the Institute the measurements that were made, and the performance that was observed. 


\section{Description of experimental biogas plant}

The experimental biogas plant consists of two parts: (i) the biogas plant proper and (ii) an instrumentation pit.

The biogas plant is of a KVIC design for a daily output of 200 cubic $\mathrm{ft}\left(5.66 \mathrm{~m}^{3}\right)$ of biogas.* The masonry digester is $1.98 \mathrm{~m}$ in diameter and $4.88 \mathrm{~m}$ deep. A partition wall separates this cylindrical digester pit into two halves. The gas holder consists of an inverted 'drum', $1.83 \mathrm{~m}$ wide and $1.22 \mathrm{~m}$ high, made of 12 gauge $(0.27 \mathrm{~cm})$ thick mild steel. The gas holder floats up and down on a central guide frame fixed to the partition wall. In addition, the plant has an above-ground inlet tank for charging slurry, and a below-ground outlet tank for receiving the processed sludge. These features of the biogas plant are shown in figure 1 .

A pit of the same dimensions as the digester, and adjoining it, has been provided to accommodate the instrumentation for studies on temperature, density and $\mathrm{pH}$ distribution inside the digester. In particular, the instrumentation pit permits access to the digester via portholes through which samples can be withdrawn and thermocouples can be inserted. For locating the thermocouples at desired places in the digester, an aluminium framework is rigidly fixed to the concrete bed of the digester. GI pipes of $19 \mathrm{~mm}$ diameter have been embedded in the digester wall at intervals of $30.5 \mathrm{~cm}$ to permit the slurry to be withdrawn for analysis and for density and $\mathrm{pH}$ measurements. The $7.6 \mathrm{~cm}$ diameter pipes going through the digester wall at two positions are connected to a centrifugal pump which can be used for draining the slurry. These details are shown in figure 2.

\section{Observations}

The instrumented biogas plant has been in operation for about $2 \frac{1}{2}$ years since December 1976 when charging with cattle dung was commenced. The regular operation consists of the following activities:

(i) weekly analysis** of the dung for total volatile solids,

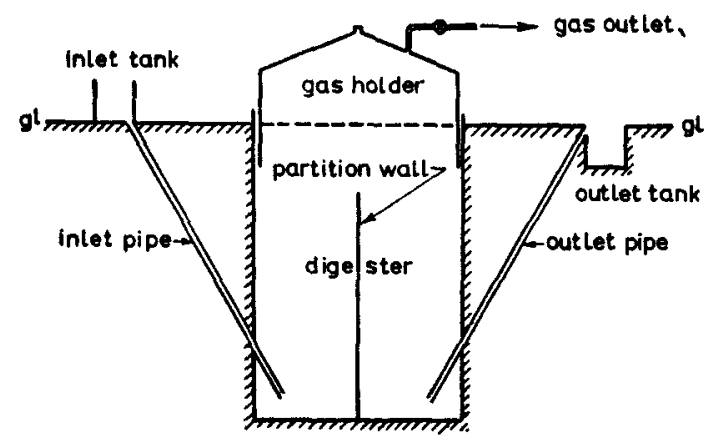

Figure 1. Biogas plant

*Unfortunately, the operating temperature corresponding to the rated capacity is not stated, but presumably it is $25^{\circ} \mathrm{C}$.

**Initially, the analysis was carried out daily. 

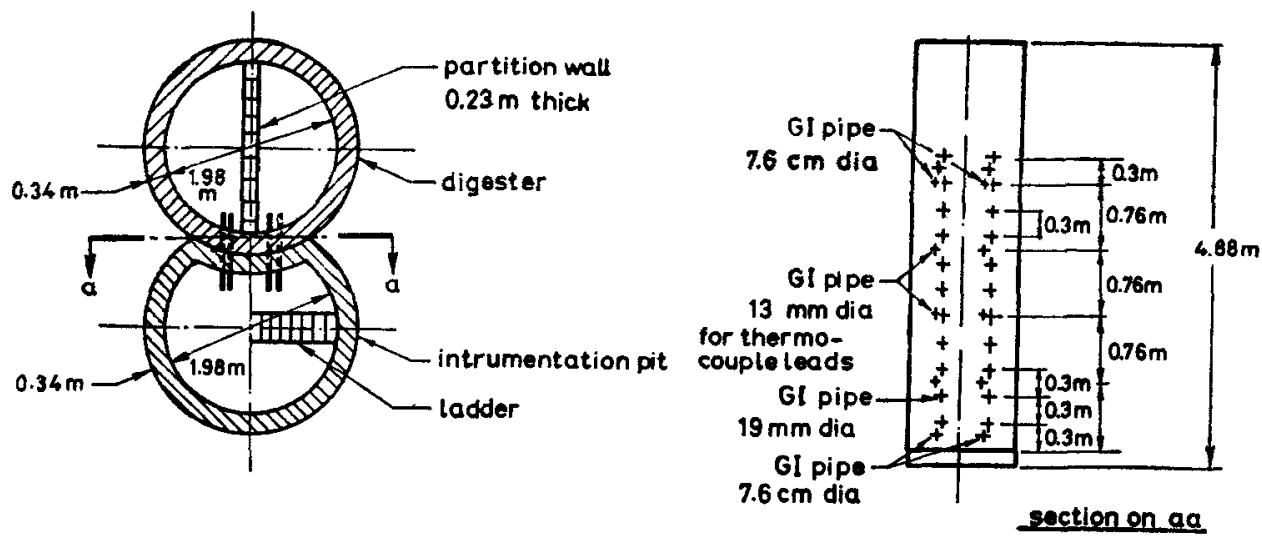

Figure 2. Details of digester and instrumentation pit

(ii) daily charging the plant with fresh dung (less than one-day old) made into a $1: 1$ (by weight) mixture with water,

(iii) daily measurement of the gas yield over $24 \mathrm{hr}$ periods,

(iv) daily measurement of the weight of slurry displaced by the charging of slurry.

In addition, the following measurements were made for specific periods.**

(i) daily estimation of carbon and nitrogen in the influent and effluent for about a month,

(ii) daily estimation of the $\mathrm{CO}_{2}$ percentage in biogas for the initial six months, and of the $\mathrm{H}_{2} \mathrm{~S}$ content for about a month,

(iii) daily measurement of the temperature at 32 locations, and density and $\mathrm{pH}$ at 18 locations each, inside the digester for about six months.

The information obtained from these measurements will now be described in detail, the particular values reported below being averaged over a six-month period of observation from January to June 1977.

\subsection{Input to biogas plant}

The analysis of the cattle dung which was supplied to the biogas plant by a local vendor is shown in figure 3.

It is known (Meynell 1976) that the optimum solids content for anaerobic fermentation is $8-10 \%$ which is the basis for diluting the cattle dung, which has a total solid content of $17 \%$ in an approximately $1: 1$ ratio.

The optimum carbon/nitrogen $(\mathrm{C} / \mathrm{N})$ ratio has been reported to be 25 (Meynell 1976) in contrast to the value of 16 in the present experiments, but no attempt was made to alter the $\mathrm{C} / \mathrm{N}$ ratio in the input by means of additions (e.g. straw) because it was a deliberate objective in this study to observe the plant performance with an input of cattle dung only. ${ }^{*} *$

\footnotetext{
*The measurements were restricted to limited periods because constant trends were observed, which made further measurements unnecessary.

**Most of the 60,000 biogas plants in the country operate solely with cattle dung.
} 


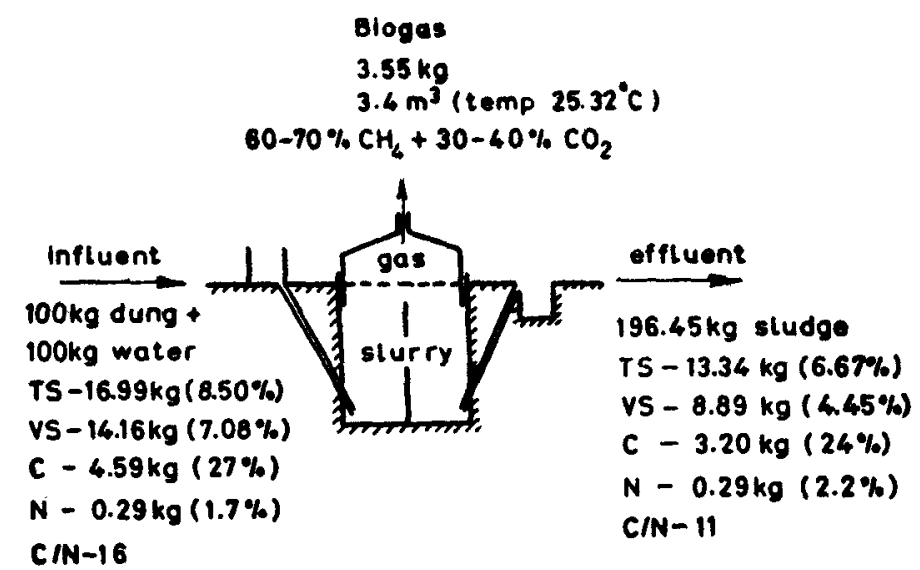

Figure 3. Mass balance of a biogas plant

Over the six-month period during which the mass balance was worked out (see figure 3), the cattle dung was charged into the plant at the rate of $122 \pm 5 \mathrm{~kg}$ fresh dung per day.

\subsection{Sludge output}

The fresh sludge, which is the effluent from the plant, yielded the analysis shown in figure 3. It can be seen that there was a reduction of $21.4 \%$ and $37.14 \%$ in total solids and volatile solids respectively. These observed values are in reasonable agreement with the literature values of $33 \%$ and $36 \%$ respectively (Jewell et al 1976).

The nitrogen percentage which was taken on a dry weight basis in the fresh sludge i.e., $2.2 \%$ was more than that in the input, viz., $1.7 \%$, but this increase can be simply explained by the reduction in total solids.

The effect of storing fresh sludge and cattle dung in the open air was also studied (Rajabapaiah 1979). On keeping, the nitrogen content of cattle dung fell from an initial value of $1.7 \%$ to a final value of $0.9 \%$ in about 10 days after which it remains constant. In contrast, the corresponding value for sludge effluent decreased from $2.2 \%$, to a constant $1.9 \%$ in about 3 days. Thus, sludge dried for more than about 3 days had a nitrogen content which was $2 \cdot 1$ times the value for cattle dung stored (for manurial purposes) in the open for more than about 10 days.

\subsection{Biogas output}

The average yield of biogas over the six-month period of observation was $4.15 \mathrm{~m}^{3} /$ day (146.5 cubic ft/day) and the gas composition was about $60 \% \mathrm{CH}_{4}$ and $40 \% \mathrm{CO}_{2} . \mathrm{H}_{2} \mathrm{~S}$ was observed to the extent of $0.06 \%$. During this period, the mean ambient temperature was $25 \cdot 32^{\circ} \mathrm{C}$.

The average biogas yield per unit input of cattle dung was $0.034 \mathrm{~m}^{3} / \mathrm{kg}$ wet dung corresponding to $0.200 \mathrm{~m}^{3} / \mathrm{kg}$ dry dung or total solids. The yield can also be expressed as $0.24 \mathrm{~m}^{3} / \mathrm{kg}$ volatile solids. These values compare well with the yields reported by the KVIC (Anon 1974).

It must be noted, however, that the actual biogas yield from the plant was $27 \%$ 
less than its rated value of $5.66 \mathrm{~m}^{3} /$ day. Even when the charging rate was stepped up to $150 \mathrm{~kg}$ fresh dung/day, the biogas yield was $24 \%$ of this rated value.

\subsection{Conditions inside the digester}

The slurry density was approximately within $3 \%$ of the density of water at all the 18 points inside the digester where daily measurements were made for about 5 months. Incidentally, the slurry density was between the density of influent $(1.03 \mathrm{~g} / \mathrm{cc})$ and that of the effluent $(0.97 \mathrm{~g} / \mathrm{cc})$. Thus, there was hardly any stratification of density inside the digester.

The slurry $\mathrm{pH}$ was 6.90 throughout the digester, though the influent $\mathrm{pH}$ was 7.01 .

The temperature at all the 32 points where it was measured, i.e., at 4 planes $(1.5$, $2 \cdot 3,3$ and $3.8 \mathrm{~m}$ depths) and 8 locations on each plane, was constant to within $1^{\circ} \mathrm{C}$, and virtually identical to the mean ambient temperature. As in the case of density, the temperature also was virtually uniform inside the digester.

\subsection{Long term performance}

After about $1 \frac{1}{2}$ years of operation, considerable difficulty was experienced in pushing in the daily charge and in withdrawing slurry samples through the lowest porthole on the inlet side. When the porthole was opened, it was found that coarse sand, obviously from the input dung, had built up at the bottom of the digester to a height of at least $0.3 \mathrm{~m}$. This observation not only reveals an important operational problem, but also underlines the need to charge sand-free dung or to have some sand-removing precaution.

Another interesting observation arose from an unforeseen reduction in dung supply, during which the average biogas yield fell to $2 \cdot 11 \mathrm{~m}^{3} /$ day, followed by a total stoppage of dung supply for a period of 18 days. The following response of the biogas plant was observed: the gas yield dropped gradually over this period from the value of $2 \cdot 11$ $\mathrm{m}^{3} /$ day to $0.97 \mathrm{~m}^{3} /$ day. Further, when regular charging was resumed, the gas yield slowly built up to the normal value. This result is an indication of the slow response of biogas plants to fluctuations in dung inputs.

\section{Discussion}

On the basis of these studies, certain conclusions can be drawn:

(i) Over the long period of observation, the conventional biogas plant has consistently yielded at $25.32^{\circ} \mathrm{C}$ about $25 \%$ less gas than its rated capacity of 5.66 $\mathrm{m}^{3} /$ day, ${ }^{*}$ though the gas yield per unit weight of cattle dung $\left(0.200 \mathrm{~m}^{3} / \mathrm{kg}\right.$ total solids) is not lower than what is reported by the designers of the plant. The shortfall in gas yield appears to have little to do with the daily charging rate-even when the latter was increased by $22 \%$, the shortfall only decreased by $3 \%$. Thus, the capacity of the conventional plant for cattle-dung inputs appears to be overrated.

(ii) The observations testify to the ability of the plant to withstand reduction and

*Assuming that this rating is for a temperature of about $25^{\circ} \mathrm{C}$. 
cessation in dung supply. In addition, the plant is exceedingly easy to operate, and has thus far offered virtually no maintenance problems (the gas holder has been painted only once in the $2 \frac{1}{2}$ years and shows little corrosion). These factors of stability of performance and ease of operation supplement the already powerful arguments for an intensification in the use of biogas energy.

(iii) The sustained observation over a period of about 6 months of markedly uniform conditions of density and temperature in the digester imply that, inside the reactor, there is hardly any stratification worth mentioning. The almost complete uniformity of density and temperature inside the biogas plant is an unexpected result, for it is generally believed that there is a significant extent of stratification. In fact, it is this belief which has influenced the dimensioning of biogas plants, which is a matter discussed in the next part of the paper.

(iv) Conventional biogas plants are fed daily-thus, they are not ideal batch reactors. However, the feeding of input is only for about $30 \mathrm{~min}$, whereas all data are averaged over at least $24 \mathrm{hr}$; hence, for about $98 \%$ of its life, a biugas plant experiences a batch operation.

The daily charging of input into conventional biogas plants leads to the daily displacement of sludge - thus, flow conditions exist only for this brief period, i.e., these plants are not constant flow reactors.

In view of the daily loading, and the resulting perturbations inside the digester, conventional plants are not in a perfect steady-state.

There is a decrease in total solid content from a value of about $8.5 \%$ in the input to about $6.8 \%$ in the displaced sludge. This change in input and output compositions is associated with a $6 \%$ decrease in density, from an influent density which is $3 \%$ higher than the density of water to an effluent density which is $3 \%$ lower than that of water. Hence, the density throughout the digester is within $3 \%$ of the value of that of water, i.e., it is almost uniform. The temperature inside the digester is maintained by the heat transfer processes (cf. part III of this paper) at values which are within $1^{\circ} \mathrm{C}$ of the mean ambient temperature. The production of biogas from an 'infinite' number of uniformly and randomly distributed sources facilitates this homogeneous temperature distribution. Notwithstanding the isothermal and virtually uniform density conditions inside the digester, it may not be correct to describe a conventional biogas plant as an ideal mixed reactor because the concentration of total/volatile solids is almost certain to vary between the entry and exit regions of the digesters.

In conclusion, therefore, conventional biogas plants are neither ideal batch nor constant flow reactors. Also, they are not in perfect steady-state, and they are most probably not completely mixed. A more rigorous characterisation requires further investigation of transient behaviour, diffusive transport, spatial variations of the concentrations of total/volatile solids, generated acids, bacteria, etc. Tentatively, a conventional biogas plant may be viewed as an isothermal, 'uniform' density, most probably imperfectly mixed, fed-batch reactor operating at the mean ambient temperature and the density of water.

The authors wish to thank Professors K Krishna Prasad and C R Prasad for help in the design of the instrumented plant, and Shri K R Nayak for help in fabrication. Thanks are due to Dr C V Seshadri (Shri A M M Murugappa Chettiar Research 
Centre) and Professor R Kumar (Indian Institute of Science) for their valuable comments on the characterisation of the biogas reactor. They would also like to express their special gratitude to Professor M V Narasimhan who was responsible for the overall co-ordination of the project and generously shouldered all the onerous administrative burdens. This work has been funded by the Tata Energy Research Institute to whom the authors are indebted for invaluable support.

\section{References}

Anon 1974 Gobar gas; why and how (Bombay: Khadi \& Village Industries Commission)

Jewell W J, Davis H R, Gunkel W W, Lathwell D J, Martin Jr J H, McCarty T R, Morris G R, Price D R \& Williams D W 1976 Bioconversion of agricultural wastes for pollution control and energy conservation, Final report from New York State College of Agriculture and Life Sciences, Cornell University (NTIS TID-27164)

Kirsch E J \& Sykes R M 1971 Prog. Ind. Microbiol 9155

Makhijani A \& Poole A 1975 Energy and agriculture in the third world (Cambridge, Mass: Ballinger) Meynell P J 1976 Methane: planning a digester (London: Prism)

Prasad C R, Krishna Prasad K \& Reddy A K N 1974 Economic and Political Weekly 91347

Pyle L 1978 in Biogas technology in the third world: A multidisciplinary review eds A Barnett, L Pyle and S K Subramanian (Ottawa: Int. Dev. Res. Centre)

Rajabapaiah P 1979 Private communication

Reddy A K N \& Krishna Prasad K 1977 Economic and Political Weekly 121465 